PROF. PATRICK MARCELLIN (Orcid ID : 0000-0001-8950-0287)

Article type : Original Articles

\title{
Manuscript
}

Proposed title Ten-year efficacy and safety of tenofovir disoproxil fumarate
treatment for chronic hepatitis $B$ virus infection

\section{Authors and} affiliations

Professor Patrick Marcellin MD ${ }^{1}$, Dave Wong MD², Professor

William Sievert $\mathrm{MD}^{3}$, Peter Buggisch $\mathrm{MD}^{4}$, Professor Jörg Petersen

$M^{4}$, Professor Robert Flisiak MD ${ }^{5}$, Professor Michael Manns

$M D^{6,7}$, Kelly Kaita $\mathrm{MD}^{8}$, Professor Zahari Krastev $\mathrm{MD}^{9}$, Professor

Samuel S Lee MD ${ }^{10}$, Andrea L Cathcart PhD ${ }^{11}$, Gerald Crans

$\mathrm{PhD}^{11}$, Marjoleine Op den Brouw PhD ${ }^{12}$, Belinda Jump $\mathrm{MD}^{11}$, Anuj

Gaggar $M^{11}$, John Flaherty PharmD ${ }^{11}$, Professor Maria

Buti-Ferret MD ${ }^{13}$

1. Viral Hepatitis Research Unit, Hôpital Beaujon, Clichy, France

2. Toronto Centre for Liver Disease, University Health Network, University of Toronto, Toronto, Ontario, Canada

3. Gastroenterology and Hepatology Unit, Monash Health and Monash University, Melbourne, Australia

4. Liver Unit, IFI-Institute for Interdisciplinary Medicine, Asklepios Klinik St Georg, Hamburg, Germany

5. Department of Infectious Diseases and Hepatology, Medical University Bialystok, Bialystok, Poland

6. Department of Gastroenterology, Hepatology, and Endocrinology, Hannover Medical School, Hannover, Germany

7. Helmholtz Center for Infection Research (HZI), Braunschweig, Hannover, Germany

8. Viral Hepatitis Investigative Unit, University of Manitoba, Winnipeg, Canada

This article has been accepted for publication and undergone full peer review but has not been through the copyediting, typesetting, pagination and proofreading process, which may lead to differences between this version and the Version of Record. Please cite this article as doi: 10.1111/liv.14155

This article is protected by copyright. All rights reserved. 
9. Clinic of Gastroenterology, St Ivan Rilsky University Hospital, Medical University, Sofia, Bulgaria

10. Liver Unit, University of Calgary, Calgary, Alberta, Canada

11. Gilead Sciences Inc., Foster City, USA

12. Gilead Sciences Europe Ltd., Uxbridge, UK

13. Liver Unit, Hospital Universitario Vall d'Hebron and CIBEREHD del Instituto Carlos III, Barcelona, Spain

\section{Corresponding/lead Patrick Marcellin}

author and contact Viral Hepatitis Research Unit, Hôpital Beaujon, Clichy, France

details

Telephone: +33 (1) 616967292

Email: patrick.marcellin@aphc.info

\section{Target journal Liver International}

\section{Abbreviations $\quad$ TDF: tenofovir disoproxil fumarate; CHB: chronic hepatitis B;}

HBeAg: hepatitis B e antigen; ALT: alanine aminotransferase; HBV: hepatitis B virus; HCC: hepatocellular carcinoma; HBsAg: hepatitis B surface antigen; anti-HBs: hepatitis B surface antibody; ETV: entecavir; TAF: tenofovir alafenamide; ADV: adefovir dipivoxil; mITT: modified intention-to-treat; FTC: emtricitabine; ULN: upper limit of normal; HBV pol/RT: HBV reverse transcriptase; AE: adverse event; NA: nucleos(t)ide analogue; PEG-IFN: pegylated interferon; BMD: bone mineral density; TFV: tenofovir; OL: open-label extension period

Conflict of interest Patrick Marcellin reports grants and personal fees from Gilead declarations Sciences, Bristol-Myers Squibb, and Genfit and grants from Janssen, Merck Sharp \& Dohme, and AbbVie, outside the submitted work; David K Wong has nothing to disclose; William Sievert reports grants from Gilead Sciences, during the conduct of the study; Peter Buggisch reports personal fees from Gilead Sciences, Bristol-Myers Squibb, AbbVie, Janssen, and Merck Sharp \& Dohme, outside the submitted work; Jörg Petersen reports personal fees from Gilead Sciences and Bristol-Myers Squibb, during the conduct of the study; Robert Flisiak reports grants and personal fees from Gilead 
Sciences and Roche and personal fees from Bristol-Myers Squibb,

outside the submitted work;

Michael Manns reports personal fees and other from Roche GlaxoSmithKline, Enyo Pharma, Curevac, Medgenics and BristolMyers Squibb and grants, personal fees, and other from Gilead Sciences and Novartis, during the conduct of the study; Kelly Kaita reports personal fees from Gilead Sciences, Merck Sharp \& Dohme, and AbbVie, outside the submitted work; Zahari Krastev has nothing to disclose; Samuel S Lee reports grants and personal fees from AbbVie, Bristol-Myers Squibb, Gilead Sciences, Janssen, Idenix, Merck Sharp \& Dohme, Vertex, Roche, and Boehringer Ingelheim, outside the submitted work; Andrea L Cathcart was an employee and stockholder of Gilead Sciences at the time this research was performed; Gerald Crans, Marjoleine Op den Brouw, Belinda Jump, Anuj Gaggar and John Flaherty are all employees and stockholders of Gilead Sciences; Maria Buti reports grants and personal fees from Gilead Sciences, outside the submitted work.

Financial support This work was supported by Gilead Sciences. Medical writing support was provided by Bryony Connor and Dr Liesje Quine, Elements Communications Ltd, and funded by Gilead Sciences.

Statement of contribution of each author The study was designed and conducted according to the protocol by the sponsor (Gilead Sciences) in collaboration with the principal investigators. The sponsor collected the data, monitored the study conduct and performed the statistical analyses. All authors were involved in data acquisition and analysis, interpretation of the data, and contributed to drafting the manuscript and critical revision of the manuscript with regards to important intellectual content. All authors approved the final version of the manuscript prior to submission. The corresponding author had full access to all the data and the final responsibility for the decision to submit for publication.

Acknowledgements We would like to thank the patients who participated, and all the centres and researchers who contributed to this long study. 


\section{ABSTRACT}

Background \& Aims: Tenofovir disoproxil fumarate (TDF) is a first-line treatment for chronic hepatitis $B(\mathrm{CHB})$. We aimed to describe the efficacy and safety profiles of TDF treatment for up to 10 years in a well-described cohort of CHB patients.

Methods: Hepatitis B e antigen ( $\mathrm{HBeAg})$-negative and HBeAg-positive patients from two randomised, double-blind trials (ClinicalTrials.gov: NCT00117676 and NCT00116805) completed 48 weeks of randomised treatment with TDF or adefovir dipivoxil. A subset of these patients was then eligible to receive open-label TDF treatment for up to 10 years. At Year 10, patients were assessed for virological suppression, alanine aminotransferase (ALT) normalisation, serological response, safety, and tolerability.

Results: Of 641 randomised and treated patients, 585 (91\%) entered the open-label extension phase with 203 (32\%) patients completing Year 10 of the study. At Year 10, $118 / 118(100 \%)$ of HBeAg-negative patients and 78/80 (98\%) of HBeAg-positive patients with available data achieved hepatitis B virus (HBV) DNA <69 IU/mL, while 88/106 (83\%) and 60/77 (78\%) patients achieved ALT normalisation, respectively. Of the 23 patients with HBeAg status available at Year 10, 12 (52\%) and six (27\%) experienced HBeAg loss and seroconversion, respectively. No resistance to TDF was documented up to Year 10. In the period between Year 8 and Year 10, the safety profile of TDF was similar to previous reports, with few patients experiencing renal- or bone-related adverse events.

Conclusions: Over 10 years, TDF had a favourable safety profile, was well tolerated, and resulted in continued maintenance of virological suppression with no documented resistance.

\section{KEY WORDS}

TDF, hepatitis B, long-term

This article is protected by copyright. All rights reserved. 


\section{LAY SUMMARY}

Since treatment options for chronic hepatitis $B(\mathrm{CHB})$ can only control replication of the hepatitis B virus, rather than result in cure, the majority of $\mathrm{CHB}$ patients require lifelong treatment to continually suppress viral replication and prevent progression to chronic liver disease or hepatocellular carcinoma. Therefore, long-term data on therapies for CHB are highly valuable. Results from this study demonstrate that tenofovir disoproxil fumarate treatment for up to 10 years is well tolerated, effectively suppresses viral replication, and leads to sustained biochemical, serological, and clinical responses with no detectable resistance

\section{INTRODUCTION}

Chronic hepatitis $B(\mathrm{CHB})$ infection is an important global health threat and a major cause of cirrhosis and hepatocellular carcinoma (HCC) worldwide. ${ }^{1}$ While treatment with currently available agents does not result in a functional cure of CHB, i.e. sustained loss of hepatitis $B$ surface antigen (HBsAg) with or without seroconversion to hepatitis B surface antibody (anti-HBs), in the majority of instances, long-term oral antiviral therapy suppresses hepatitis $B$ virus (HBV) replication which leads to slowing or prevention of disease progression. ${ }^{2,3} \mathrm{~A}$ number of effective oral antiviral agents are available for the treatment of $\mathrm{CHB}$, with entecavir (ETV), tenofovir disoproxil fumarate (TDF), and, more recently, tenofovir alafenamide (TAF), being the current antiviral treatments recommended by most major guidelines. $^{1-3}$

Previously, data from two multicentre, randomised, double-blind, Phase 3 studies, which enrolled 641 patients, showed TDF to have superior antiviral efficacy compared with that of adefovir dipivoxil (ADV) over 48 weeks of treatment in both hepatitis B e antigen (HBeAg)negative and $\mathrm{HBeAg}$-positive patients. After the randomised phase of this study, patients were able to either continue on open-label TDF or were switched from ADV to open-label TDF for a planned additional 7 years. ${ }^{4}$ Analyses conducted at Year 5 showed that viral suppression was achieved in 65\% (160/248) and 83\% (291/350) of HBeAg-positive and HBeAg-negative patients, respectively (modified intention-to-treat [mITT], missing equal to failure/addition of emtricitabine [FTC] equal to failure) with $97 \%$ and $99 \%$ of these patients who had remained on treatment achieving HBV DNA $<69 \mathrm{IU} / \mathrm{mL}$ at this time point. Importantly, improvement in liver fibrosis was achieved after 5 years of treatment in $51 \%$ of patients, with $74 \%(71 / 96)$ of patients with cirrhosis at baseline showing reversal of cirrhosis. ${ }^{5}$ After 8 years of treatment, 58\% (139/241) and 75\% (261/348) of HBeAg-positive 
and HBeAg-negative patients achieved HBV DNA $<69 \mathrm{IU} / \mathrm{mL}$ (mITT), respectively. By Kaplan-Meier analysis, rates of HBsAg loss were $13 \%$ and $1 \%$, respectively while $32 \%$ and $21 \%$ of $\mathrm{HBeAg}$-positive patients experienced loss of HBeAg and seroconversion, respectively. ${ }^{6}$ Treatment was well tolerated and there was a low incidence of renal events in these analyses. ${ }^{4,5}$

Just before completion of the Year 8 analysis, both study protocols were amended to extend open-label TDF treatment for two additional years (i.e. to Year 10) which allowed a subset of patients (i.e. those who consented to participate prior to reaching the Year 8 endpoint) to continue treatment. Here we describe long-term experience with TDF in the cohort of patients who received continuous therapy for up to 10 years.

\section{METHODS}

The designs of the two randomised, controlled studies, GS-US-174-0102 (NCT00117676; Study 102) and GS-US-174-0103 (NCT00116805; Study 103), have been described previously. ${ }^{4}$ Briefly, the studies enrolled HBeAg-negative (Study 102) or HBeAg-positive (Study 103) CHB patients (18-69 years of age) with compensated liver disease and Knodell necroinflammatory score $\geq 3.4$. Patients were randomised 2:1 to receive TDF $300 \mathrm{mg}$ once daily or ADV $10 \mathrm{mg}$ once daily. After 1 year of treatment, all patients entered the open-label phase where they were either switched to or continued on TDF for an additional 7 years (384 weeks total duration). The follow-up period for these studies was subsequently extended to 10 years ( 480 weeks) for the subset of patients who had consented to continue treatment. FTC could also be added to the treatment regimen, at the discretion of the investigator, if a patient experienced confirmed detectable HBV DNA on or after 1.5 years (Week 72). All patients gave their written informed consent before any procedures were performed. This study was also approved by independent ethics committees or institutional review boards at the study sites, in accordance with the principles stated in the Declaration of Helsinki.

This article is protected by copyright. All rights reserved. 


\section{Outcomes}

Efficacy assessments at Year 10 included the proportion of patients with plasma HBV DNA $<69 \mathrm{IU} / \mathrm{mL}$ ( $<400$ copies/mL) and the proportion of patients with plasma HBV DNA $<29 \mathrm{IU} / \mathrm{mL}$ ( $<169$ copies/mL; the lower limit of quantification of the COBAS TaqMan assay). Biochemical and serological responses were assessed as previously described. ${ }^{4}$ Biochemical response was defined as normal alanine aminotransferase (ALT) levels $(\leq 34$ $\mathrm{IU} / \mathrm{mL}$ for women and $\leq 43 \mathrm{IU} / \mathrm{mL}$ for men) at the end of follow-up in patients with baseline ALT values above the upper limit of normal (ULN). Serological endpoints included serum HBeAg loss and seroconversion (HBeAg-positive patients), and serum HBsAg loss and seroconversion to anti-HBs. Patients with confirmed HBsAg loss or seroconversion could stop treatment at the investigator's discretion, provided they remained on follow-up. Resistance testing was performed by population sequencing of the HBV reverse transcriptase (HBV $\mathrm{pol} / \mathrm{RT}$ ) and was conducted annually or at the time of early study drug discontinuation for patients with HBV DNA $\geq 69 \mathrm{IU} / \mathrm{mL}$. Phenotyping was performed in these patients to confirm findings for conserved site changes occurring in at least one patient and any polymorphic site change in more than one patient as previously described. ${ }^{6}$

Safety and tolerability assessments including adverse events (AEs), treatment discontinuations, and patient deaths were conducted throughout the study and cumulatively reported for those occurring during the open-label phase. Predefined renal endpoints included confirmed (upon re-testing) creatinine clearance $<50 \mathrm{~mL} / \mathrm{min}$, serum creatinine $\geq 0.5 \mathrm{mg} / \mathrm{dL}$ above baseline, and serum phosphate $<2 \mathrm{mg} / \mathrm{dL}$.

\section{Statistical analysis}

Virological and biochemical responses for the total study period were assessed using ontreatment (observed) analysis, in which patients with missing data were excluded from the analysis and patients who had FTC added were included. This descriptive approach was deemed most appropriate given the high attrition rate for subjects after Year 8, which was due mostly to lack of consent to extend participation for an additional 2 years.

This article is protected by copyright. All rights reserved. 


\section{RESULTS}

\section{Patient disposition}

A total of 203/641 (32\%) HBeAg-positive and HBeAg-negative patients who were initially randomised and treated remained in the study at Year 10 (Figure 1). The most frequent reasons given for discontinuation over the whole study period were withdrawal of consent ( $n=94)$; loss to follow-up $(n=56)$; investigator decision $(n=33)$; and safety, tolerability, or efficacy reasons $(n=28)$. More than one reason for discontinuation was possible. In these clinical trials, the yearly withdrawal rate related to investigator decision and safety, tolerability, or efficacy reasons and was approximately $1 \%$ regardless of the period of treatment. During the entire study period, ten patients discontinued treatment following HBsAg or HBeAg seroconversion; including two during the randomised phase and eight during the open-label phase (on or before Year 8 [Week 384]).

\section{Virological response}

In patients who remained on TDF treatment at Year 10, 198 had virological data available. High rates of HBV DNA suppression to $<69 \mathrm{IU} / \mathrm{mL}$ and $<29 \mathrm{IU} / \mathrm{mL}$ ( $99 \%$ with both cut-offs) were achieved, including $100 \%$ of $\mathrm{HBeAg}$-negative patients and $97.5 \%$ of $\mathrm{HBeAg}$-positive patients (Table 1).

\section{Biochemical response}

At Year 10, of the 183 patients with data available, normal ALT levels were observed in $81 \%$ of patients ( $83 \%$ and $77 \%$ in $\mathrm{HBeAg}$-negative and $\mathrm{HBeAg}$-positive patients, respectively) (Table 1). Of the 203 patients completing Year 10 of the study, 25.5\% had ALT levels persistently <ULN throughout the entire follow-up period and $74.5 \%$ had some increase in ALT (generally transient and mild). Of the patients included in the 10-year follow-up analyses, $93 \%$ of patients $(n=188)$ had abnormal ALT levels at baseline. Of these, $52 \%$ had normal body mass index ( $<25 \mathrm{~kg} / \mathrm{m}^{2}$ ); $33 \%$ were overweight ( $\geq 25$ to $\geq 30 \mathrm{~kg} / \mathrm{m}^{2}$ ); and $15 \%$ were obese $\left(>30 \mathrm{~kg} / \mathrm{m}^{2}\right)$ at baseline, respectively.

\section{Serological response}

HBeAg status was available in 23 patients (initially HBeAg-positive) who remained on treatment at Year 10. HBeAg loss and seroconversion was achieved by 52\% (12/23) and $27 \%(6 / 22)$ of patients, respectively. HBsAg loss was observed in four HBeAg-positive patients and four HBeAg-negative patients during the 10-year study period; all were nonAsian with either HBV genotype A or D infection. Transient HBsAg loss was observed in four 
additional patients whose HBsAg levels were low and fluctuated throughout the study period.

\section{Resistance analysis}

Viral resistance surveillance was conducted annually and the sequence analysis for the 88 patients that qualified at one or more time points through Year 8 have been previously described. ${ }^{6}$ Five HBeAg-positive patients and three HBeAg-negative patients qualified for sequence analysis during Year 9, with seven of the eight patients achieving HBV DNA <69 $\mathrm{IU} / \mathrm{mL}$ at Year 10 , and one patient discontinuing with no sequence change in the HBV pol/RT from baseline. During Year 10, four HBeAg-positive patients qualified; one had polymorphic site changes and three had no sequence changes in the HBV pol/RT from baseline.

\section{Safety analysis}

A summary of safety findings during the open-label period (cumulative) is shown in Table 2. Of the 585 patients who entered the open-label phase, 11 patients $(2 \%)$ withdrew due to AEs. Seven out of the 11 patients withdrew due to AEs that were related to the study drug. Reasons for discontinuation (in some cases multiple) for these patients included fatigue $(n=1)$, increased blood creatine phosphokinase $(n=1)$, abdominal pain $(n=1)$, increased blood creatinine $(n=1)$, breast cancer $(n=1)$, disturbance in attention $(n=1)$, dizziness $(n=1)$, drug dependence $(n=1)$, endometrial cancer $(n=1), \operatorname{HCC}(n=1)$, nausea $(n=1)$, osteoporosis $(n=1)$, and septic shock $(n=1)$. Over the 10-year study period, HCC occurred in 17 patients, with four cases occurring between Years 6 and 10. Of these four patients, two were cirrhotic at baseline. By Year 10, 18 deaths had occurred (none were considered study drug related). Causes of death were non-liver carcinoma $(n=10), \operatorname{HCC}(n=4)$, cardiovascular disease $(n=2)$, and motor vehicle accident $(n=2)$.

A total of 41 fractures occurred in 34 patients; 18 had signs of osteopenia or osteoporosis in parts of the hip or spine; however, only four reports of osteoporosis as an AE were recorded. Of the patients who reported osteoporosis as an $A E$, three were male and one female, their ages ranged from 29-63 years, and all had renal parameters within the normal range. Overall, no clinically relevant bone loss was observed during the 4-year follow-up period.

This article is protected by copyright. All rights reserved. 


\section{DISCUSSION}

Our analysis confirms the long-term efficacy of TDF in patients with CHB. The analysis includes data from patients who had been treated for up to 10 years with TDF and is the only study with such long-term follow-up of treated CHB patients. TDF treatment resulted in high levels of virological suppression and was well tolerated with few discontinuations related to AEs. In addition, no resistance to TDF was documented and no new safety signals were identified after 10 years.

HBsAg loss is considered to be the ideal endpoint of therapy because it indicates suppression of both HBV replication and viral protein expression and is, therefore, associated with better clinical outcomes. ${ }^{8}$ Unfortunately, HBsAg loss is achieved infrequently with the currently available anti-HBV agents, including TDF. ${ }^{3}$ In this long-term cohort analysis, the number of patients experiencing HBsAg loss was low at the end of follow-up (4\%), but included both baseline HBeAg-positive $(n=4)$ and HBeAg-negative $(n=4)$ patients. Other study groups have reported similar low rates of HBsAg loss when treating with different oral antiviral agents (such as ETV and telbivudine) for 4-5 years, including rates of $1.4-5.2 \%$ in $\mathrm{HBeAg}-$ positive patients and $0.6-4.6 \%$ in HBeAg-negative patients. ${ }^{9-11}$

More rapid rates of HBsAg decline have been reported with combinations of nucleos(t)ide analogue (NA) + pegylated interferon (PEG-IFN) and higher rates of HBsAg loss have been also been reported at Week 72 with TDF + PEG-IFN combination therapy compared with TDF or PEG-IFN alone (9.1\% vs $0 \%$ and $2.8 \%$, respectively). ${ }^{12,13}$ However, given the lack of long-term follow-up to assess the potential for higher rates of HBsAg loss with combination strategies, the present data are insufficient to support such a change in clinical treatment strategy. ${ }^{13}$ Other combination therapy approaches have not increased rates of HBsAg loss substantially. ${ }^{14-16}$

As rates of HBsAg loss with NAs are low, sustained virological suppression (defined here as HBV DNA levels $<29 \mathrm{IU} / \mathrm{mL}$ ) is the most clinically relevant endpoint because it is associated with prevention of disease progression. ${ }^{3}$ In this study, HBV DNA levels were regularly assessed over 10 years (every 4 weeks to Week 48, every 8 weeks to Week 96, and every 12 weeks thereafter). This is consistent with the 2017 EASL guidelines which recommend that during the first year of treatment, serum HBV DNA should be determined at least every 3-4 months and every 6-12 months thereafter. ${ }^{3}$ Over the 10 years that this study was conducted, HBV DNA levels were consistently supressed below $29 \mathrm{IU} / \mathrm{mL}$. These data, in 
combination with previous studies that show no evidence of resistance to long-term TDF therapy, suggest that in adherent patients on TDF therapy, annual or biannual HBV DNA testing may potentially be sufficient. ${ }^{6,17}$ This may be of particular relevance in resourcelimited settings.

Regression of cirrhosis and prevention of HCC were also important clinical outcomes in these long-term TDF studies. A previous analysis of the studies reported here provided pivotal data that demonstrated regression of fibrosis and reversal of cirrhosis in virologically suppressed patients during TDF therapy at Year 5, and that the incidence of HCC was reduced compared with predicted rates using the REACH-B calculator. ${ }^{5,18}$ Throughout this 10-year study, rates of HCC remained low and no patients underwent liver transplantation. Of the 17 patients who developed HCC, 12 had baseline Ishak fibrosis scores between 4 and 6 indicating that they had advanced fibrosis or cirrhosis at baseline. However, it is known that the presence of macronodular cirrhosis can be underestimated. ${ }^{19}$ There are many risk factors associated with the development of HCC, but the presence of cirrhosis is the most prominent. ${ }^{20}$ Although the risk of developing HCC in this study was low, there is still a need for ongoing surveillance, especially in those patients with initially bridging fibrosis or cirrhosis.

ALT levels are commonly used as an indicator of liver function in patients with $\mathrm{CHB}^{21,22}$ with elevated ALT levels often indicating serious liver disease. ${ }^{23}$ Previous analyses suggest that oral antiviral therapy leads to ALT normalisation in the majority of patients, ${ }^{4,10,11}$ an outcome shown to result in a lower risk of subsequent hepatic events compared with patients with continually elevated ALT levels. ${ }^{22}$ ALT normalisation can be affected by a variety of factors including sex, body mass index (BMI), hepatic steatosis and presence of metabolic syndrome. ${ }^{23,24}$ In our analysis, $81 \%$ of patients achieved ALT normalisation, with the presence of hepatic steatosis assumed to be the cause of continually elevated ALT in some patients.

This study adds to the considerable amount of data demonstrating the well-tolerated safety profile of TDF, ${ }^{3,25,26}$ however changes in renal function were reported in some patients. $5.1 \%$ of patients experienced renal impairment over the 10 -year period, which is within the range previously reported for NA therapies (2-7\%). ${ }^{16,26,27}$ The renal effects observed during TDF treatment have been attributed to the accumulation of tenofovir (TFV) within proximal tubular cells following oral administration. ${ }^{28}$ It is therefore recommended that patients 
treated with TDF undergo periodical renal monitoring. Patients with decompensated cirrhosis, hypertension, proteinuria, diabetes mellitus, active glomerulonephritis and those receiving concomitant nephrotoxic drugs or solid organ transplantation have an increased risk of renal impairment and therefore close monitoring is required in these patients, regardless of the prescribed treatment. ${ }^{3}$

TAF, a prodrug of TFV, has now been designed to optimise delivery of active TFV to hepatocytes and thus reduce systemic exposure to TFV. ${ }^{29,30}$ Recent publications show that renal safety profiles are improved with TAF compared with TDF after 1 year of treatment. ${ }^{31}$ 32

With regards to bone mineral density (BMD), patients with $\mathrm{CHB}$ have been shown to be at greater risk of developing osteoporosis than matched non-HBV-infected controls. ${ }^{33,34}$ Therefore, the previously reported changes in BMD with TDF therapy, although small $(\leq 2 \%)$, suggest that BMD should be serially assessed. ${ }^{5}$ The long-term safety assessment of TDF in these two studies included measurement of BMD between Years 4 and 8 and showed little further decline in this parameter. Unfortunately, lacking baseline assessments of BMD, the changes we previously reported are difficult to interpret. ${ }^{16}$ We observed single or multiple bone fractures in 34 patients, however only four reports of osteoporosis as an $\mathrm{AE}$ were recorded.

Our analysis has some limitations including that only one-third of patients originally randomised remained in the study at Year 10 and the population was pre-selected by virtue of an amendment to the study protocol. However, despite the substantial attrition of patients at Year 8, this remains the largest long-term controlled trial of antiviral therapy, including TDF use, in patients with CHB.

In conclusion, in this study, which included the longest follow-up period of CHB patients treated with oral antiviral agents to date, we show that long-term TDF treatment for up to 10 years was well tolerated and effectively suppressed viral replication without development of resistance in patients with $\mathrm{CHB}$.

This article is protected by copyright. All rights reserved. 


\section{REFERENCES}

1. World Health Organization. Guidelines on hepatitis B and C testing, 2017. http://apps.who.int/iris/bitstream/10665/254621/1/9789241549981-eng.pdf?ua=1 Accessed February 18, 2019

2. Terrault NA, Lok A, McMahon B, et al. Update on prevention, diagnosis and treatment of chronic hepatitis B: AASLD 2018 hepatitis B guidance. Hepatology 2018;67:1560-99

3. European Association for the Study of the Liver. EASL 2017 Clinical Practice Guidelines: Management of chronic hepatitis B virus infection. J Hepato/ 2017;67:370-98

4. Marcellin P, Heathcote EJ, Buti M, et al. Tenofovir disoproxil fumarate versus adefovir dipivoxil for chronic hepatitis B. N Engl J Med 2008;359:2442-55

5. Marcellin P, Gane E, Buti M, et al. Regression of cirrhosis during treatment with tenofovir disoproxil fumarate for chronic hepatitis B: a 5-year open-label follow-up study. Lancet 2013;381:468-75

6. Liu Y, Corsa AC, Buti M, et al. No detectable resistance to tenofovir disoproxil fumarate in $\mathrm{HBeAg}+$ and $\mathrm{HBeAg}$ - patients with chronic hepatitis $\mathrm{B}$ after 8 years of treatment. $J$ Viral Hepat 2017;24:68-74

7. Knodell RG, Ishak KG, Black WC, et al. Formulation and application of a numerical scoring system for assessing histological activity in asymptomatic chronic active hepatitis. Hepatology 1981;22:696-9

8. Moucari R, Marcellin P. Quantification of hepatitis B surface antigen: a new concept for the management of chronic hepatitis B. Liver Int 2011;31:122-8

9. Ahn J, Lee HM, Lim JK, et al. Entecavir safety and effectiveness in a national cohort of treatment-naïve chronic hepatitis B patients in the US - the ENUMERATE study. Aliment Pharmacol Ther 2016;43:134-44

10. Wang Y, Thongsawat S, Gane EJ, et al. Efficacy and safety of continuous 4-year telbivudine treatment in patients with chronic hepatitis B. J Viral Hepat 2013;20:e37-46

11. Chang TT, Lai CL, Kew Yoon S, et al. Entecavir treatment for up to 5 years in patients with hepatitis B e antigen-positive chronic hepatitis B. Hepatology 2010;51:422-30

This article is protected by copyright. All rights reserved. 
12. Marcellin P, Lau GK, Bonino F, et al. Peginterferon alfa-2a alone, lamivudine alone, and the two in combination in patients with HBeAg-negative chronic hepatitis B. N Eng/ J Med 2004;351:1206-17

13. Marcellin $\mathrm{P}$, Ahn $\mathrm{SH}$, Ma $\mathrm{X}$, et al. Combination of tenofovir disoproxil fumarate and peginterferon a-2a increases loss of hepatitis $B$ surface antigen in patients with chronic hepatitis B. Gastroenterology 2016;150:134-44

14. Brouwer WP, Xie Q, Sonneveld MJ, et al. Adding pegylated interferon to entecavir for hepatitis $B$ e antigen-positive chronic hepatitis $B$ : a multicentre randomized trial (ARES Study). Hepatology 2015;61:1512-22

15. Lai CL, Leung N, Teo EK, et al. A 1-year trial of telbivudine, lamivudine, and the combination in patients with hepatitis $B$ e antigen-positive chronic hepatitis $B$. Gastroenterology 2005;129:528-36

16. Marcellin $\mathrm{P}$, Wursthorn $\mathrm{K}$, Wedemeyer $\mathrm{H}$, et al. Telbivudine plus pegylated interferon alfa-2a in a randomized study in chronic hepatitis $B$ is associated with an unexpected high rate of peripheral neuropathy. $J$ Hepato/ 2015;62:41-7

17. Buti M, Tsai N, Petersen J, et al. Seven-year efficacy and safety of treatment with tenofovir disoproxil fumarate for chronic hepatitis B virus infection. Dig Dis Sci 2015;60:1457-64

18. Kim WR, Loomba R, Berg $T$, et al. Impact of long-term tenofovir disoproxil fumarate on incidence of hepatocellular carcinoma in patients with chronic hepatitis B. Cancer $2015 ; 121: 3631-8$

19. Bedossa P, Dargère D, Paradis V. Sampling variability of liver fibrosis in chronic hepatitis C. Hepatology 2003;38:1449-57

20. Idilman R, Gunsar F, Koruk M, et al. Long-term entecavir or tenofovir disoproxil fumarate therapy in treatment-naïve chronic hepatitis B patients in the real-world setting. $J$ Viral Hepat 2015;22:504-10

21. Feld JJ, Wong DK, Heathcote EJ. Endpoints of therapy in chronic hepatitis B. Hepatology 2009;49:S96-S102

22. Wong GL, Chan HL, Tse YK, et al. Normal on-treatment ALT during antiviral treatment is associated with a lower risk of hepatic events in patients with chronic hepatitis B. $J$ Hepato/ 2018;69:793-802 
23. Sarin SK, Kumar M. Should chronic HBV infected patients with normal ALT be treated: debate. Hepatol Int 2008;2:179-84

24. Jacobson IM, Washington MK, Buti M, et al. Factors associated with persistent increase in level of alanine aminotransferase in patients with chronic hepatitis $B$ receiving oral antiviral therapy. Clin Gastroenterol Hepatol 2017;15:1087-94

25. Wong GL, Chan HL, Tse YK, et al. Chronic kidney disease progression in patients with chronic hepatitis B on tenofovir, entecavir, or no treatment. Aliment Pharmacol Ther 2018;48:984-92

26. Fung S, Kwan P, Fabri M, et al. Randomized comparison of tenofovir disoproxil fumarate vs emtricitabine and tenofovir disoproxil fumarate in patients with lamivudine-resistant chronic hepatitis B. Gastroenterology 2014;146:980-8

27. Fung $S$, Kwan $P$, Fabri $M$, et al. Tenofovir disoproxil fumarate (TDF) versus TDF/emtricitabine (FTC) in lamivudine-resistant hepatitis B: a 5-year randomized study. $J$ Hepato/ 2017;66:11-8

28. Seto WK, Asahina Y, Brown TT, et al. Improved bone safety of tenofovir alafenamide compared to tenofovir disoproxil fumarate over 2 years in patients with chronic HBV infection. Clin Gastroenterol Hepato/ 2018; published online June 19. DOI:

10.1016/j.cgh.2018.06.023

29. Babusis D, Phan TK, Lee WA, Watkins WJ, Ray AS. Mechanism for effective lymphoid cell and tissue loading following oral administration of nucleotide prodrug GS-7340. Mol Pharm 2013;10:459-66

30. Murakami E, Wang T, Park Y, et al. Implications of efficient hepatic delivery by tenofovir alafenamide (GS-7340) for hepatitis B virus therapy. Antimicrob Agents Chemother 2015;59:3563-9

31. Buti M, Gane E, Seto WK, et al. Tenofovir alafenamide versus tenofovir disoproxil fumarate for the treatment of patients with $\mathrm{HBeAg-negative} \mathrm{chronic} \mathrm{hepatitis} \mathrm{B} \mathrm{virus}$ infection: a randomised, double-blind, phase 3, non-inferiority trial. Lancet Gastroenterol Hepato/ 2016;1:196-206

32. Chan $\mathrm{HL}$, Fung $\mathrm{S}$, Seto $\mathrm{WK}$, et al. Tenofovir alafenamide versus tenofovir disoproxil fumarate for the treatment of HBeAg-positive chronic hepatitis B virus infection: a randomised, double-blind, Phase 3, non-inferiority trial. Lancet Gastroenterol Hepatol 2016;1:185-95

This article is protected by copyright. All rights reserved. 
33. Chen $\mathrm{CH}$, Lin $\mathrm{CL}$, $\mathrm{Kao} \mathrm{CH}$. Association between chronic hepatitis $\mathrm{B}$ virus infection and risk of osteoporosis. Medicine (Baltimore) 2015;94:e2276

34. Gill US, Zissimopoulos A, Al-Shamma S, et al. Assessment of bone mineral density in tenofovir-treated patients with chronic hepatitis B: can the Fracture Risk Assessment tool identify those at greatest risk? J Infect Dis 2015;211:374-8

\section{FIGURES}

\section{Figure 1: Patient disposition}

\section{TABLES}

Table 1: Virological, biochemical, and serological responses to TDF in patients on treatment at Year $\mathbf{1 0}^{\dagger}$

\begin{tabular}{|l|c|c|c|}
\hline \multirow{2}{*}{} & \multicolumn{2}{|c|}{ HBeAg status $_{|c|}$ All } \\
\cline { 2 - 4 } & HBeAg-negative & HBeAg-positive $^{\S}$ & \\
\hline HBV DNA <69 IU/mL, \% (n/N) & $100(118 / 118)$ & $97.5(78 / 80)$ & $99.0(196 / 198)$ \\
\hline HBV DNA <29 IU/mL, \% (n/N) & $100(118 / 118)$ & $97.5(78 / 80)$ & $99.0(196 / 198)$ \\
\hline ALT normalisation, \% (n/N) & $83.0(88 / 106)$ & $77.9(60 / 77)$ & $80.9(148 / 183)$ \\
\hline HBeAg loss, \% (n/N) & - & $52.2(12 / 23)$ & $52.2(12 / 23)$ \\
\hline HBeAg seroconversion, \% (n/N) & - & $27.3(6 / 22)$ & $27.3(6 / 22)$ \\
\hline HBsAg loss, \% (n/N) & $3.4(4 / 117)$ & $4.9(4 / 81)$ & $4.0(8 / 198)$ \\
\hline
\end{tabular}

ALT: alanine aminotransferase; HBeAg: hepatitis B e antigen; HBV: hepatitis B virus; HBsAg: hepatitis B surface antigen

${ }^{+}$Patients with missing data were excluded and patients with emtricitabine added to their treatment regimen were included in the analysis

${ }^{\ddagger} \mathrm{HBeAg}$-negative patients enrolled in Study 102

$\S \mathrm{HBeAg}$-positive patients enrolled in Study 103

This article is protected by copyright. All rights reserved. 
Table 2: Cumulative safety profile of TDF in HBeAg-negative and HBeAg-positive patients participating in the open-label extension period up to Year 10

\begin{tabular}{|c|c|c|c|}
\hline & \multicolumn{2}{|c|}{ By initial treatment assignment } & \multirow{2}{*}{$\begin{array}{c}\text { All } \\
n=585^{+}\end{array}$} \\
\hline & $\begin{array}{c}\text { TDF-TDF } \\
n=389\end{array}$ & $\begin{array}{c}\text { ADV-TDF } \\
n=196\end{array}$ & \\
\hline Patients who discontinued due to $\mathrm{AEs}, \mathrm{n}(\%)$ & $10(2.6)$ & $1(0.5)$ & $11(1.9)$ \\
\hline Study drug-related serious AEs, n (\%) & $5(1.3)$ & $2(1.0)$ & $7(1.2)$ \\
\hline Study drug-related Grade 3 or Grade 4 AEs, n (\%) & $3(0.8)$ & $3(1.5)$ & $6(1.0)$ \\
\hline Deaths, n (\%) & $13(3.3)$ & $5(2.6)$ & $18(3.1)$ \\
\hline 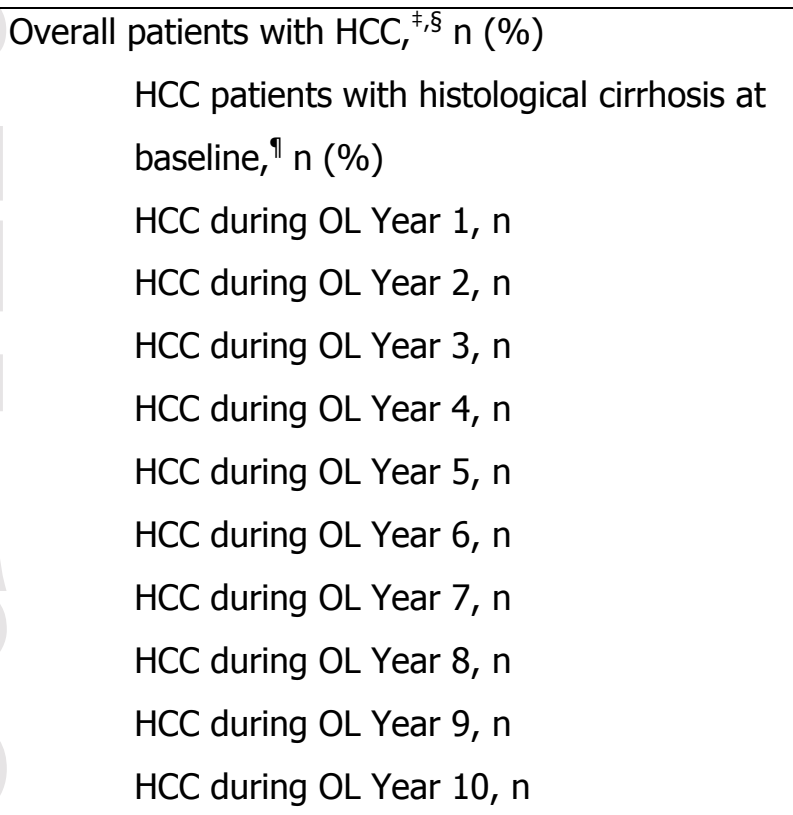 & $\begin{array}{c}11(2.8) \\
5(45.5) \\
2 \\
4 \\
2 \\
2 \\
0 \\
1 \\
0 \\
0 \\
0 \\
0\end{array}$ & $\begin{array}{c}6(3.1) \\
4(66.7) \\
0 \\
0 \\
0 \\
2 \\
1 \\
1 \\
0 \\
0 \\
2 \\
0\end{array}$ & $\begin{array}{c}17(2.9) \\
12 / 17(70.6) \\
2 \\
4 \\
2 \\
4 \\
1 \\
2 \\
0 \\
0 \\
2 \\
0\end{array}$ \\
\hline $\begin{array}{l}\text { Renal impairment, } \mathrm{n}(\%) \\
\text { Serum creatinine increase of } 0.5 \mathrm{mg} / \mathrm{dL} \\
\text { from baseline } \\
\text { Creatinine clearance }<50 \mathrm{~mL} / \mathrm{min} \\
\text { Serum phosphate }<2 \mathrm{mg} / \mathrm{dL}\end{array}$ & $\begin{array}{l}9(2.3) \\
4(1.0) \\
6(1.5)\end{array}$ & $\begin{array}{l}4(2.0) \\
3(1.5) \\
4(2.0)\end{array}$ & $\begin{array}{c}13(2.2) \\
7(1.2) \\
10(1.7)\end{array}$ \\
\hline
\end{tabular}

ADV: adefovir dipivoxil; AE: adverse event; HBeAg: hepatitis B e antigen; HCC: hepatocellular carcinoma; OL: open-label extension period; TDF: tenofovir disoproxil fumarate

${ }^{+}$Includes all subjects in the open-label safety analysis set (post-Week 48)

${ }^{\ddagger}$ MedDRA Preferred Terms for HCC were: hepatobiliary neoplasm, mixed hepatocellular

cholangiocarcinoma, liver carcinoma ruptured, hepatic cancer metastatic, hepatic cancer stages I-IV, hepatoblastoma, hepatic angiosarcoma, hepatic cancer, hepatocellular carcinoma, hepatobiliary cancer, hepatobiliary cancer in situ, hepatic neoplasm, hepatic neoplasm malignant, hepatobiliary neoplasm, hepatoblastoma recurrent and hepatic cancer recurrent

$\S$ There were three patients who had multiple HCC outcomes in the data set. They are only counted once in the table (the earliest outcome) since it is not clear if these are HCC recurrences. There was also one subject who had an HCC event during treatment-free follow-up analysis who was not included in the table above

" Cirrhosis was defined as Ishak score of 6

This article is protected by copyright. All rights reserved. 


\section{SUPPLEMENTARY APPENDIX}

Supplementary Figure 1. Kaplan-Meier analysis for survival probability of 17 HCC patients

[see separate Supplementary Figure File]

Supplementary Table 1. Demographic and baseline characteristics of the patients who completed Year 10 of treatment and patients who did not complete Year 10 [see separate Supplementary File]

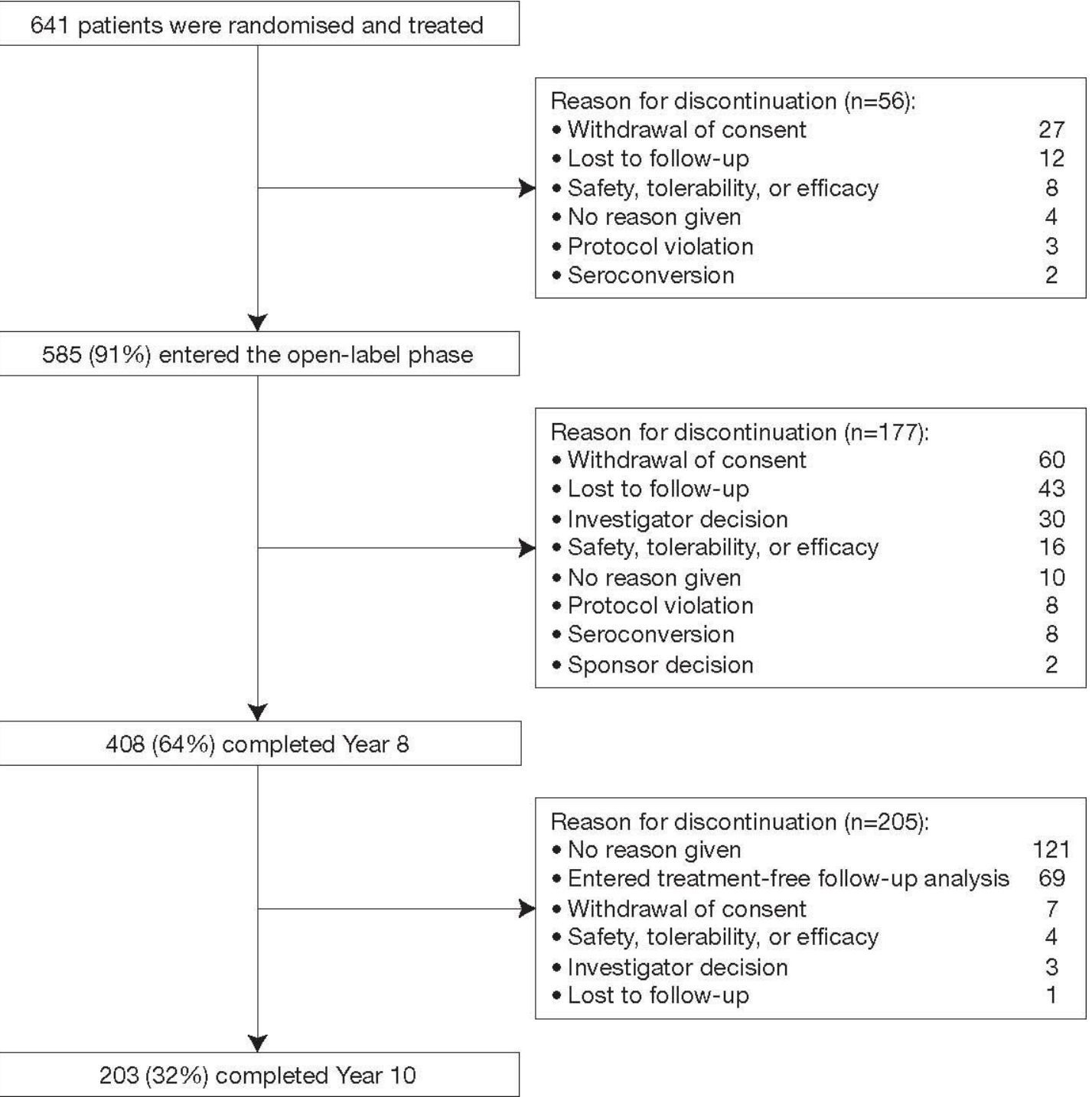

This article is protected by copyright. All rights reserved. 